\title{
Video-assisted pulmonary lobectomy combined with transmanubrial approach for anterior Pancoast tumor resection: case report
}

\author{
Lorenzo Rosso, Alessandro Palleschi, Paolo Mendogni* and Mario Nosotti
}

\begin{abstract}
Background: The mini-ivasive approach to superior sulcus tumors is an uncommon procedure that is still far from standardization. We describe a hybrid surgical technique to approach "en block" chest resection and pulmonary lobectomy for anterior superior sulcus tumors.

Case Presentation: A patient affected by right anterior Pancoast tumor surgically staged as CT4NOMO (suspected anonymous vein invasion) underwent chemo-radiation induction therapy with satisfactory tumor reduction. The surgical operation comprised an initial VATS approach to the hilar structures followed by a limited C-shaped anterior contra-incision; finally, the right upper lobe "en block" with the anterior part of the first and second rib was removed. The whole procedure was conducted with the patient in the supine position; no rib retractors were used. The definitive stage was ypTONOMO. The patient had an uneventful hospital stay and at the 9 months follow-up she was free from disease and post-thoracotomy syndrome.

Conclusions: In our opinion such hybrid VATS procedure has several advantages: starting with thoracoscopy it is possibleto exclude previously undetected pleural dissemination and to precisely define the tumor location as well as limits of the thoracic wall resection; time could be spared maintaining the patients in the supine position for both surgical times; postoperative pain and post-thoracotomy syndrome could be minimized avoiding the use of any rib retractor.
\end{abstract}

Keywords: Anterior Pancoast, VATS lobectomy, Lung cancer, Chest wall, Transmanubrial approach

\section{Background}

Thoracoscopic "en bloc" chest wall resection is a procedure not fairly usual for Video-assisted thoracoscopic surgery (VATS) lobectomy; this report describes technical details of an emerging new surgical procedure consisting in a hybrid technique for treatment of anterior Pancoast tumor.

Despite the increasing acceptance of VATS lobectomy even for advanced surgical procedures, anterior Pancoast tumors have been rarely approached with VATS combined with transmanubrial approach [1]. The first case was described by Truin in 2010, afterwards a restricted

\footnotetext{
* Correspondence: paolo.mendogni@unimi.it

Thoracic Surgery and Lung Transplant Unit, Fondazione IRCCS (Scientific Institute for Research Hospitalization and Health Care) "Ca' Granda" General Hospital University of Milan, Via Francesco Sforza, 35, Milan 20122, Italy
}

number of cases approached with hybrid procedures were reported [2-5]. In these series (6 patients), the induction therapies as well as free intervals were heterogeneous, nevertheless the follow-up was encouraging (Table 1). From the technical point of view, only Yokoyama managed the apex via the transmanubrial approach as the second surgical step as we did. The vast majority of patients underwent first rib resection; moreover, three patients had an additional bone resection. T1 root or vascular invasion management was necessary in three cases. The mean hospital stay was 13.2 days while morbidity was present in $40 \%$ of the cases. 
Table 1 Reported clinical experiences

\begin{tabular}{|c|c|c|c|c|c|c|c|c|c|c|c|c|c|c|}
\hline Author & G. & Age & Pathol. & $\begin{array}{l}\text { Clinical } \\
\text { stage }\end{array}$ & $\begin{array}{l}\text { Induction } \\
\text { therapy }\end{array}$ & $\begin{array}{l}\text { Free Interval } \\
\text { (weeks) }\end{array}$ & Technique & $\begin{array}{l}\text { Patient } \\
\text { position }\end{array}$ & Extended resection & $\begin{array}{l}\text { Pathol. } \\
\text { stage }\end{array}$ & $\begin{array}{l}\text { LOS } \\
\text { (days) }\end{array}$ & Complications & $\begin{array}{l}\text { DFI } \\
\text { (Months) }\end{array}$ & Alive \\
\hline Truin & $F$ & 60 & NSCLC & CT3NOMO & Cisplatin + etoposide & 6 & Apex first & Supine + Lateral & $\begin{array}{l}1^{\text {st }} \text { rib }+\mathrm{T} 1 \\
\text { root }+ \text { Subcl. } \\
\text { vein }\end{array}$ & ypTONOMO & 7 & $\begin{array}{l}\text { Right arm mild } \\
\text { edema }\end{array}$ & NA & NA \\
\hline Nakajima & M & 59 & NSCLC & сT3NOMO & $\begin{array}{l}\text { Cisplatin + Mitomycin } \\
\text { C + Vindesine }+45 \\
\text { Gy }\end{array}$ & 6 & Apex first & Supine & $\begin{array}{l}1^{\text {st }} \text { rib }+\mathrm{T} 1 \\
\text { root }+ \text { Scalene } \\
\mathrm{m} .\end{array}$ & ypTONOMO & NA & $\begin{array}{l}\text { Left lung atelectasis } \\
\text { Phrenic nerve } \\
\text { paralysis }\end{array}$ & NA & NA \\
\hline Shikuma & M & 59 & NSCLC & cT3NOMO & $\begin{array}{l}\text { Cisplatin + docetaxel + } \\
60 \mathrm{~Gy}\end{array}$ & NA & Apex first & Supine + Lateral & None & урT3NOMO & NA & None & 24 & yes \\
\hline \multirow[t]{3}{*}{ Yokoyama } & M & 79 & Pleom. Carc. & CT3NOMO & None & NA & VATS first & Lateral + Supine & $1^{\text {st }}+2^{\text {nd }}$ ribs & pT3NOMO R1 & 18 & None & 58 & yes \\
\hline & M & 51 & NSCLC & CT4NOMO & $\begin{array}{l}\text { Carboplatin + Paclitaxel + } \\
50 \text { Gy }\end{array}$ & 5 & VATS first & Lateral + Supine & $\begin{array}{l}1^{\text {st }} \text { rib + Subcl. } \\
\text { vein }\end{array}$ & ypT3NOMO & 17 & None & 16 & yes \\
\hline & M & 52 & NSCLC & CT4N1M0 & $\begin{array}{l}\text { Carboplatin + Paclitaxel + } \\
40 \text { Gy }\end{array}$ & 3 & VATS first & Lateral + Supine & $\begin{array}{l}\text { Clavicle }+1^{\text {st }}+ \\
2^{\text {nd }} \text { ribs }\end{array}$ & ypT4NOMO & 15 & None & 62 & yes \\
\hline $\begin{array}{l}\text { Present } \\
\text { case }\end{array}$ & $F$ & 50 & AdenoCa & CT3NOMO & $\begin{array}{l}\text { Cisplatin + Pemetrexed + } \\
60 \text { Gy }\end{array}$ & 10 & VATS first & Supine & $1^{\text {st }}+2^{\text {nd }}$ ribs & ypTONOMO & 9 & Hyperpyrexia & 6 & yes \\
\hline
\end{tabular}

$G$ gender, $F$ female, $M$ male, Pleom. Carc Pleomorphic carcinoma 


\section{Case presentation}

A 50 year-old woman with a 20 pack/years smoking history was referred to our Institution for right Pancoast tumor diagnosed as adenocarcinoma by fine needle aspiration cytology. The patient, presented with right arm pain, was staged with chest Computed Tomography (CT), brain $\mathrm{CT}$ and positron emission tomography (PET). The mediastinal and hilar nodal sampling at right thoracoscopy confirmed the NO status diagnosed by CT and PET; in addition, the involvements of the right brachiocephalic and subclavian veins were highly suspected at the pleural inspection (stage cT4N0M0). The patient was treated with four cycles of cisplatin and Pemetrexed plus 60 Gy irradiation. Re-staging showed partial tumor regression at CT while PET scan became negative (Fig. 1a). The patient was placed in supine position and the surgery commenced with a thoracoscopy to evaluate the resectability through a $10-\mathrm{mm}$ trocar in the eighth intercostal space on the midaxillary line. Once the VATS procedure was judged feasible, a 4 $\mathrm{cm}$ utility incision was made in the fourth intercostal space anteriorly to the latissimus dorsi muscle; an additional $10-\mathrm{mm}$ incision was created posteriorly to the first incision. After adhesiolysis and dissection of the caudal mediastinal lymph-node stations, the upper lobe vessels were individually divided by staplers. Afterward, a limited $\mathrm{C}$-shaped contra-incision was performed along the anterior border of the right sternocleidomastoid muscle and extended parallel to the second intercostal space. To preserve the sternoclavicular joint a vertical transmanubrial incision was made to reach the second intercostal space with a 5-6 cm extension to the right side (Fig. 1). Despite firm adhesions, there were no vascular or nervous infiltration and the apical dissection was considered complete after the resection of the anterior part of the first and second ribs, which were indissociable from the lung tumor. Through VATS accesses, sections of the right superior bronchus and the remaining fissure completed the lobectomy; the "en bloc" specimen was extracted through the apical incision. After the completion of lymphadenectomy, the sternum was sutured with metallic stitches and the anterior defect of the thoracic wall was repaired with a synthetic patch $(5 \mathrm{~cm}$ in diameter).

Postoperative pain never excided 4 on the visual analog scale; neither intraoperative nor postoperative complications were observed and the patient was discharged 9 days after surgery (pathological result: ypT0NOM0). At the twelve-month follow-up the patient was free from disease and post-thoracotomy syndrome.

\section{Discussion and conclusions}

In our opinion, the VATS procedure had several theoretical advantages. Rib retractors, known source of pain, were not used in any of the incisions; lobectomy was conducted through well-known accesses avoiding the uncommon transmanubrial adit for lobar dissection; Grunenwald contra-incision was shortened; unnecessary resection of thoracic wall was avoided. The "VATS observation first" has the advantage to exclude previously undetected pleural dissemination and to precisely define the tumor location; for instance, a needle inserted through the chest wall under endoscopic vision can help in focusing and minimizing the resection of rib segments. The majority of Authors change the patients' position during the operation; on the contrary, we experienced a simple lobar dissection with the patient in the supine position: adopting the anterior approach to the hilar structures (Copenhagen approach), there is no reason to move the parenchyma from the position that it takes naturally after exclusion from the ventilation. In addition, we avoided the time-consuming maneuvers for patient repositioning (not less than $30 \mathrm{~min}$ in our theater) and the risk of endotracheal tube displacement.

We modified the Grunenwald incision extending the sternal section to the second intercostal space and

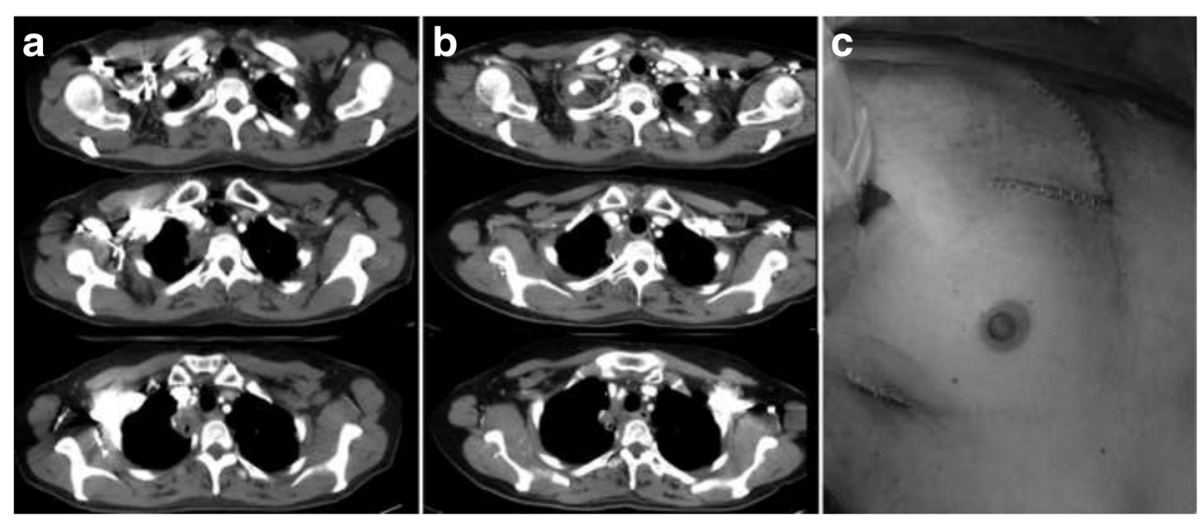

Fig. 1 a Pre-induction therapy CT scan; b Post-induction therapy CT scan; c Modified Grunenwald incision and VATS incision 
reducing the lateral extension on the caudal edge; such variation was created in order to guarantee an easy access to great venous vessels.

Despite the experiences in hybrid approach to anterior Pancoast tumors are limited and technical details are inhomogeneous, it is possible to argue that the mini-invasive surgery could be effective on these patients. We strongly support the "VATS observation first" philosophy and patient supine position to face anterior Pancoast tumor with hybrid techniques. Further studies are advisable in order to define the real advantage of hybrid approaches on open surgery.

\section{Consent}

A written consent for publication was obtained from the patient.

\section{Competing interests}

The authors declare that they have no competing interests.

\section{Authors' contribution}

LR wrote the article and participated to the surgical operation. AP collected data and contributed to the pre- and postoperative patient's management, MN wrote the article, participated to the surgery and the study design. PM wrote the article and revised manuscript. All the authors approved the final version of the manuscript.

\section{Acknowledgements}

A special thanks to Professor $\mathrm{H}$. Date for data update.

\section{Funding}

No funding was provided.

Received: 5 October 2015 Accepted: 4 April 2016

Published online: 14 April 2016

\section{References}

1. Kara HV, Balderson SS, D'Amico TA. Challenging cases: thoracoscopic lobectomy with chest wall resection and sleeve lobectomy—Duke experience. J Thorac Dis. 2014;6(S6):S637-40.

2. Truin W, Siebenga J, Belgers E, Bollen EC. The role of video-assisted thoracic surgery in the surgical treatment of superior sulcus tumors. Interact CardioVasc Thorac Surg. 2010;11:512-4.

3. Nakajima T, Watanabe A, Nakazawa J, Higami T. Transmanubrial approach with video-assisted thoracoscopic surgery for left superior sulcus tumour with dense adhesion after replacement of descending thoracic aorta. Interact Cardiovasc Thorac Surg. 2012;14(6):906-8.

4. Shikuma K, Miyahara R, Osako T. Transmanubrial approach combined with video-assisted approach for superior sulcus tumors. Ann Thorac Surg. 2012:94(1):e29-30.

5. Yokoyama Y, Chen F, Aoyama A, Sato T, Date H. Combined operative technique with anterior surgical approach and video-assisted thoracoscopic surgical lobectomy for anterior superior sulcus tumours. Interact Cardiovasc Thorac Surg. 2014;19(5):864-6.

Submit your next manuscript to BioMed Central and we will help you at every step:

- We accept pre-submission inquiries

- Our selector tool helps you to find the most relevant journal

- We provide round the clock customer support

- Convenient online submission

- Thorough peer review

- Inclusion in PubMed and all major indexing services

- Maximum visibility for your research

Submit your manuscript at www.biomedcentral.com/submit 